\title{
No Detection of Methicillin-Resistant Staphylococcus aureus in Dairy Goats
}

\author{
Ylva Persson ${ }^{1, *(\mathbb{D})}$, Stefan Börjesson ${ }^{1,2,3}\left[\right.$, , Mattias Myrenås ${ }^{1}$ and Karl Pedersen ${ }^{1}(\mathbb{D}$ \\ 1 National Veterinary Institute, 75189 Uppsala, Sweden; stefan.borjesson@sva.se (S.B.); \\ mattias.myrenas@sva.se (M.M.); karl.pedersen@sva.se (K.P.) \\ 2 Department of Biomedical and Clinical Sciences, Linköping University, 58183 Linköping, Sweden \\ 3 Public Health Agency of Sweden, 17182 Solna, Sweden \\ * Correspondence: ylva.persson@sva.se; Tel.: +46-18-674162
}

check for

updates

Citation: Persson, Y.; Börjesson, S.; Myrenås, M.; Pedersen, K. No Detection of Methicillin-Resistant Staphylococcus aureus in Dairy Goats. Dairy 2021, 2, 65-70.

https://doi.org/10.3390/ dairy2010005

Received: 24 October 2020

Accepted: 15 January 2021

Published: 23 January 2021

Publisher's Note: MDPI stays neutral with regard to jurisdictional claims in published maps and institutional affiliations.

Copyright: (C) 2021 by the authors. Licensee MDPI, Basel, Switzerland. This article is an open access article distributed under the terms and conditions of the Creative Commons Attribution (CC BY) license (https:// creativecommons.org/licenses/by/ $4.0 /)$.

\begin{abstract}
This short communication addresses the hypothesis that the prevalence of methicillinresistant Staphylococcus aureus (MRSA) is low in dairy goats in Sweden. Methicillin-resistant S. aureus is a widespread zoonotic bacterium of clinical importance in both animals and humans. In Sweden, MRSA is rare among both animals and humans. However, MRSA has been detected in a few goat herds in Sweden with a high within-herd occurrence of mecC-MRSA, but only a limited number of herds were investigated and most of them were not producing milk for human consumption. The prevalence of MRSA among dairy goat herds in Sweden is not known and a cross-sectional prevalence study was therefore conducted. A total of 22 bulk milk samples from the same number of herds, and pooled swabs from nose, mouth, and perineum from 113 goats, were collected during August and September 2019 for bacteriological investigation. After culturing on selective media, suspected isolates were confirmed as $S$. aureus using MALDI-TOF and subjected to PCR targeting the mec $A$ and mecC genes to confirm MRSA status. No samples were found to be positive for MRSA, and there are therefore no indications of a spread of MRSA in Swedish dairy goat herds.
\end{abstract}

Keywords: MRSA; caprine; milk; AMR; mecC

\section{Introduction}

Methicillin-resistant Staphylococcus aureus (MRSA) is an emerging zoonotic bacterium of clinical importance. In humans, it may cause infections that are difficult to treat due to multi-resistant strains. Animals can also develop MRSA infections, but occurrence appears generally low except for pigs where the occurrence is foremost due to carriage by healthy individuals [1]. In dairy animals, MRSA infections can cause treatment-resistant mastitis cases and act as a zoonotic hazard for the farmer/milker. The pathogenic potential can, however also be the other way around as a zooanthroponotic hazard where the farmer/milker can transmit MRSA to the animals [2]. Optimal hygiene around milking and strict biosecurity routines are therefore important measurements for reducing the risk of transferring MRSA between animals and between humans and animals, within and between herds. MRSA has previously been detected in goat herds in Sweden, with a high within-herd occurrence of MRSA, but only a few herds were investigated at that time and most of them were not producing milk for human consumption [3]. Interestingly, the occurrence in these herds was due to mecC-MRSA, which is a variant of MRSA first described in 2011 from humans in Ireland [4] and from dairy cattle and humans in England, Scotland, and Denmark [5]. A recent Austrian study also described that $8 \%$ of the goats were positive with mecC-MRSA, and with mecC-MRSA only identified in goats of the ruminants sampled in that study [6].

Interestingly the occurrence of mecC-MRSA appears foremost to be connected to Europe, and overall, the occurrence appears low, but an increasing trend has been reported in humans in Denmark [7-9]. However, a high occurrence of mecC-MRSA has been described 
in wild European hedgehogs (Erinaceus europaeus) in Sweden and Denmark [10,11]. It has, therefore, been suggested that the wild European hedgehog could act as a natural reservoir for mecC MRSA. Before the description of the high occurrence in European hedgehogs, it had already been hypothesized that mecC-MRSA could be connected to wildlife [7]. That mecC-MRSA could be a wildlife-associated (WA)-MRSA is further supported by a recent publication from Spain that showed a relatively high occurrence in wild lagomorphs [12]. However, whether mecC-MRSA is a WA-MRSA remains to be elucidated as well as any potential link between goats and hedgehog mecC-MRSA occurrence (Börjesson unpublished). Besides hedgehogs and goats, there also appears to be a connection to dairy cattle. It has been shown to occur among dairy cow herds in Great Britain [8] and a few cow-associated cases of mecC-MRSA have also been identified in Sweden [13], but the incidence is much lower compared to that described for goats, wild hedgehogs, and lagomorphs. In Sweden, artisan cheese is the main product of dairy goat herds. The dairy is often located in close proximity to the goat stalls with the same personnel working both with the goats and the cheese production. Cheese and other products, sometimes produced from unpasteurized milk, are often sold directly to consumers visiting the farm. Moreover, it is also common to offer the possibility for cheese buyers to pet the goats while visiting the farm. In many parts of Sweden, especially in the north, the dairy goat sector is an important part of local tourism, due to an increased interest in local food [14]. It is therefore important to ensure a safe experience for visitors to the dairy goat farms, which includes decreasing the risk of transmitting pathogens like MRSA. But also, to inform goat farmers to protect their goats from being infected with zoonotic pathogens originating mainly from the visitors' hands or clothes. Despite the identification and high in-herd occurrence of mecC-MRSA in several Swedish goat herds, the prevalence of MRSA among dairy goat herds in Sweden is not known. The present cross-sectional study was therefore conducted on 22 dairy goat herds to study the occurrence of MRSA.

\section{Materials and Methods}

Twenty-two dairy goat herds from different geographic locations (from the very north to the very south), a sample representative for goat dairy production in Sweden, were included in the study (See Figure 1 for the geographic location of all included farms). There is no reliable official record for dairy goat herds in Sweden so an open call aiming for recruiting herds was distributed through the Swedish goat association, the Swedish artisan dairy association and on selected Facebook groups. All farms that replied to the call were recruited for the study. Data on breed, number of milking goats, type of production (dairy or household), use of disposable milking gloves (yes/no), individual udder cloths (yes/no), and teat dip (yes/no) was recorded by the farmer in a short questionnaire. From each herd, one bulk milk sample was collected in a sterile test tube (according to instructions at www.sva.se), and pooled individual swabs from up to 6 goats/herd were collected from nose, mouth, and perineum using ESwabs ${ }^{\mathrm{TM}}$ (Copan Diagnostics, Corona, CA, USA). The farmer (or employees) collected all samples and sent them by post to the National Veterinary Institute (SVA) the same day. Farmers were instructed to collect samples on Monday to Wednesday to avoid post transport delays. The samples were transported at room temperature and arrived at the SVA within $24 \mathrm{~h}$. In total, 22 bulk milk samples were taken, and 113 goats were swabbed during August and September 2019.

From the milk samples, $5 \mathrm{~mL}$ was added to $45 \mathrm{~mL}$ Mueller-Hinton broth (MHB) with $6.5 \% \mathrm{NaCl}$ and thereafter incubated at $37 \pm 1{ }^{\circ} \mathrm{C}$ overnight. From the swabs, $0.5 \mathrm{~mL}$ suspension fluid was added to $4.5 \mathrm{~mL} \mathrm{MHB}$ with $6.5 \% \mathrm{NaCl}$, and thereafter incubated at $37 \pm 1{ }^{\circ} \mathrm{C}$ overnight. All overnight enrichments showed turbidity and were considered positive for bacterial growth. From the overnight enrichments, $50 \mu \mathrm{L}$ was evenly spread on Brilliance MRSA2 (Oxoid, Thermo Fisher Scientific, Basingstoke, United Kingdom) and incubated for $18-24 \mathrm{~h}$ at $37 \pm 1^{\circ} \mathrm{C}$ according to the manufacturer's instructions. In samples from three farms, denim-blue colonies were found on the selective agar plates. The colonies were cultivated on blood agar plates and confirmed as S. aureus using Matrix-assisted laser 
desorption/ionization time-of-flight mass spectrometry (MALDI-TOF) (Bruker Daltonics, Bremen, Germany), essentially as described by [15]. The isolates were subjected to PCR targeting the mecA and mecC genes to confirm MRSA status [16] and they were all negative. White colonies growing on the agar-plate were considered as non-aureus and were not further analyzed. The quality of the Brilliance MRSA2 selective agar plates was tested using reference strains CCUG 15915 and CCUG 35601 (Culture Collection University of Gothenburg, Gothenburg, Sweden).

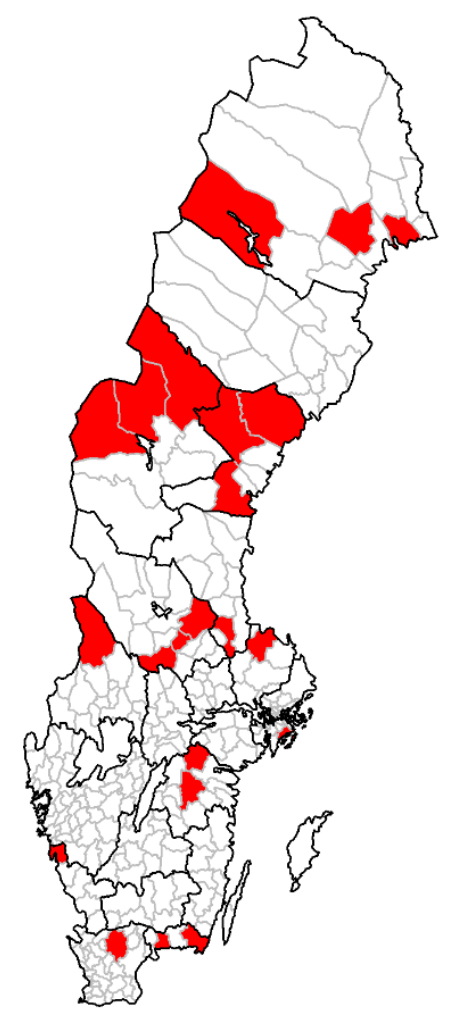

Figure 1. Geographic location of 22 goat dairy farms from different parts of Sweden. The red color indicates the municipality for each herd and not the exact coordinates.

\section{Results and Discussion}

In the 22 herds included, the mean herd size was 35 goats (range 2-114). The dominant breed was Swedish (Scandinavian) landrace (17 herds, $77.3 \%$ ) followed by various minor local breeds (Göinge (a southern breed), Jämtlandic (a central-northern breed), and Lappish (the most northern breed) breeds, unspecified, mixed breeds or crossbreeds. Sixteen herds $(72.7 \%)$ had their own artisan dairy, while six herds used their milk only for household purposes. Five herds $(22.7 \%)$ used disposable milking gloves and seventeen did not. Nineteen herds (86.4\%) used individual milking cloths, of them, fifteen used disposable cloths and four used cloths made by fabric, and three did not use individual milking cloths. Eight herds (36.4\%) used teat dip and fourteen did not. All adult goats in Sweden are, according to legislation, kept on pasture in the summertime. Most dairy goats in Sweden are machine milked and most are kept in loose housing systems although this was not included in the questionnaire. The results of the short questionnaire indicated that some biosecurity measurements around milking can be improved, although the practice to use individual milking cloths seemed to be widely implemented. Optimal milking hygiene is important for decreasing the risk of spreading contagious pathogens like MRSA between animals and between the milker and the animals (and vice versa).

This is to our knowledge the first study investigating the occurrence of MRSA in dairy goat herds in Sweden. However, after the selective screening, no samples were found to be positive for MRSA, which is in line with a study from Poland on goat bulk 
milk and a Danish study where no MRSA in goats was identified $[17,18]$. Although in the Danish study the number of goats was limited and only swabs were sampled. Other studies have, however, showed the occurrence of MRSA in goats, but with a large variation between countries. In a study from Jordan, $11.5 \%$ of the tested bulk milk samples from dairy goat herds were positive for mecA-MRSA [19]. In two studies from Italy, the bulk milk prevalence was 0.6 and $2 \%$, respectively $[20,21]$. On an individual goat level, the MRSA prevalence has been described to range from 2\% in the US and Saudi Arabia to $8 \%$ in Austria, $16 \%$ in Tenerife, Spain, and 23\% in Nigeria [2,22-25]. However, a direct comparison of the occurrence between studies should be done with care since different methods for sampling and detection are used in different studies. The reason for the variation in prevalence between countries can also be due to multiple causes, but differences in the occurrence in human and livestock populations, the use of antibiotics, hygiene practices, and disease control likely influence the occurrence. Dairy goats in Sweden are in general healthy with good udder health and a low prevalence of $S$. aureus udder infections, few underlying diseases, good management, high milk yield, and a very low antibiotic use (National Veterinary Institute 2020, www.sva.se). According to recommendations from the Swedish Veterinary Association [26], benzylpenicillin is advocated as the first choice when treating most infectious diseases. Farmers are also recommended to cull goats with S. aureus intramammary infections (IMI). In a previous study on dairy goats in Sweden, $8 \%$ of positive IMI samples were S. aureus and $50 \%$ of the herds had bulk milk samples PCR positive for $S$. aureus [27]. In the current study, the aim was only to investigate the occurrence of MRSA, thus a selective agar detecting only MRSA was used and, therefore, the occurrence of $S$. aureus sensitive to methicillin in the herds is not known.

There is a lack of reliable and up-to-date data on the number of dairy goat herds in Sweden, but in the most recent data from the Swedish Board of Agriculture [28], the number of farms that milked their goats was 230, which is less than $10 \%$ of the total goat population in Sweden. Furthermore, at least half of the farms are small scale and use the milk mainly for household purposes. The number of commercial dairy farms can therefore be estimated to be 115 with a total of 3340 goats [28]. Therefore, a limitation of our study is that it only covers a minor proportion of the dairy goat herds in Sweden, but on the other hand it represents most parts of the country and also the regions with the most dairy herds. Nevertheless, the results indicate that there is no spread of MRSA in Swedish dairy goat herds, which is a relief for Swedish dairy goat farmers. However, the fact that MRSA occurs in Sweden and that mecC-MRSA has previously been identified in a few goat herds, combined with the results of this study, emphasizes the need for continued implementation of effective biosecurity and hygiene practices for the herds to remain free from MRSA in the future. Swedish dairy goat farmers, especially farms open for visitors, need to be aware of the risk of transferring MRSA between humans and goats if good biosecurity routines are not addressed properly.

\section{Conclusions}

In this study on 22 herds, no milk or swab samples were found to be positive for MRSA, and there are therefore no indications of a spread of MRSA in Swedish dairy goat herds.

Author Contributions: Conceptualization, Y.P., S.B., M.M. and K.P.; Methodology, Y.P., S.B., M.M. and K.P.; Formal Analysis, Y.P., S.B. and K.P.; Investigation, Y.P., S.B., M.M. and K.P.; Resources, Y.P., S.B., M.M. and K.P.; Data Curation, Y.P.; Writing-Original Draft Preparation, Y.P.; Writing—Review \& Editing, Y.P., S.B., M.M. and K.P.; Project Administration, Y.P.; Funding Acquisition, Y.P. All authors have read and agreed to the published version of the manuscript.

Funding: This research was funded by Stiftelsen Ivar och Elsa Sandberg stipendiefond för livsmedelshygienisk forskning.

Institutional Review Board Statement: Ethical review and approval were waived for this study, since this type of sampling (swabs) does not require any ethical approvement, according to Swedish 
(SJVFS 2019:9, chapter 2 § 17-18) and EU legislations (2010/63/EU, article 1:5: "practices not likely to cause pain, suffering, distress or lasting harm equivalent to, or higher than, that caused by the introduction of a needle in accordance with good veterinary practice".

Informed Consent Statement: Information and consent for sampling was given by the goat owners before entering the study.

Data Availability Statement: The datasets used and analyzed during the current study are available from corresponding author on reasonable request.

Acknowledgments: We want to acknowledge the lab technicians at the antibiotic section at SVA and the participating goat farmers. We also want to thank Gunnar Andersson at SVA for excellent creation of the map. We would especially like to acknowledge and dedicate this article to Associate Professor Helle Ericsson Unnerstad who was the initial PI of this study before she so sadly passed away.

Conflicts of Interest: The authors declare no conflict of interest.

\section{References}

1. Bal, A.M.; Coombs, G.W.; Holden, M.T.G.; Lindsay, J.A.; Nimmo, G.R.; Tattevin, P.; Skov, R.L. Genomic insights into the emergence and spread of international clones of healthcare-, community- and livestock-associated meticillin-resistant Staphylococcus aureus: Blurring of the traditional definitions. J. Glob. Antimicrob. Resist. 2016, 6, 95-101. [CrossRef]

2. Unnerstad, H.E.; Mieziewska, K.; Börjesson, S.; Hedbäck, H.; Strand, K.; Hallgren, T.; Landin, H.; Skarin, J.; Bengtsson, B. Suspected transmission and subsequent spread of MRSA from farmer to dairy cows. Vet. Microbiol. 2018, 225, 114-119. [CrossRef]

3. Unnerstad, H.E.; Ahl, I.; Persson, Y.; Börjesson, S.; Bengtsson, B. High occurrence of mecC-MRSA in two goat herds in Sweden. In Proceedings of the International Symposium on Staphylococci and Staphylococcal Infections, Copenhagen, Denmark, 23-26 August 2018; p. 265.

4. Shore, A.C.; Deasy, E.C.; Slickers, P.; Brennan, G.; O'Connell, B.; Monecke, S.; Ehricht, R.; Coleman, D.C. Detection of staphylococcal cassette chromosome mec type XI carrying highly divergent mecA, mecI, mecR1, blaZ, and ccr genes in human clinical isolates of clonal complex 130 methicillin-resistant Staphylococcus aureus. Antimicrob. Agents Chemother. 2011, 55, 3765-3773. [CrossRef] [PubMed]

5. Garcia-Alvarez, L.; Holden, M.T.; Lindsay, H.; Webb, C.R.; Brown, D.F.; Curran, M.D.; Walpole, E.; Brooks, K.; Pickard, D.J.; Teale, C.; et al. Meticillin-resistant Staphylococcus aureus with a novel mecA homologue in human and bovine populations in the UK and Denmark: A descriptive study. Lancet Infect. Dis. 2011, 11, 595-603. [CrossRef]

6. Schauer, B.; Krametter-Frötscher, R.; Knauer, F.; Ehricht, E.; Monecke, S.; Feßler, A.T.; Schwarz, S.; Grunert, T.; Spergser, J.; Loncaric, I. Diversity of methicillin-resistant Staphylococcus aureus (MRSA) isolated from Austrian ruminants and New World camelids. Vet. Microbiol. 2018, 215, 77-82. [CrossRef] [PubMed]

7. Becker, K.; Ballhausen, B.; Köck, R.; Kriegeskorte, A. Methicillin resistance in Staphylococcus isolates: The "mec alphabet" with specific consideration of mecC, a mec homolog associated with zoonotic S. aureus lineages. Int. J. Med. Microbiol. 2014, 7, 794-804. [CrossRef] [PubMed]

8. Paterson, G.K.; Morgan, F.J.E.; Harrison, E.M.; Peacock, S.J.; Parkhill, J.; Zadoks, R.N.; Holmes, M.A. Prevalence and properties of mecC methicillin-resistant Staphylococcus aureus (MRSA) in bovine bulk tank milk in Great Britain. J. Antimicrob. Chemother. 2014, 3, 598-602. [CrossRef] [PubMed]

9. Petersen, A.; Stegger, M.; Heltberg, O.; Christensen, J.; Zeuthen, A.; Knudsen, L.K.; Urth, T.; Sorum, M.; Schouls, L.; Larsen, J.; et al. Epidemiology of methicillin-resistant Staphylococcus aureus carrying the novel mecC gene in Denmark corroborates a zoonotic reservoir with transmission to humans. Clin. Microbiol. Infect. 2013, 19, E16-E22. [CrossRef]

10. Bengtsson, B.; Persson, L.; Ekström, K.; Unnerstad, H.E.; Uhlhorn, H.; Börjesson, S. High occurrence of mecC-MRSA in wild hedgehogs (Erinaceus europaeus) in Sweden. Vet. Microbiol. 2017, 207, 103-107. [CrossRef] [PubMed]

11. Rasmussen, S.L.; Larsen, J.; van Wijk, R.E.; Jones, O.R.; Berg, T.B.; Angen, Ø. European hedgehogs (Erinaceus europaeus) as a natural reservoir of methicillin-resistant Staphylococcus aureus carrying mecC in Denmark. PLoS ONE 2019, 9, e0222031. [CrossRef]

12. Moreno-Grúa, E.; Pérez-Fuentes, S.; Viana, D.; Cardells, J.; Lizana, V.; Aguiló, J.; Selva, L.; Corpa, J.M. Marked Presence of Methicillin-Resistant Staphylococcus aureus in Wild Lagomorphs in Valencia, Spain. Animals 2020, 10, 1109. [CrossRef] [PubMed]

13. Unnerstad, H.E.; Bengtsson, B.; Af Rantzien, M.H.; Börjesson, S. Methicillin-resistant Staphylococcus aureus containing mecC in Swedish dairy cows. Acta Vet. Scand. 2013, 55, 6. [CrossRef] [PubMed]

14. Rytkönen, P.; Bonow, M.; Johansson, M.; Persson, Y. Goat cheese production in Sweden-A pioneering experience in the re-emergence of local food. Acta Agric. Scand. Sect. B Soil Plant Sci. 2013, 63, 38-46. [CrossRef]

15. Nonnemann, B.; Svennesen, L.; Lyhs, U.; Kristensen, K.A.; Klaas, I.C.; Pedersen, K. Bovine mastitis bacteria resolved by matrix-assisted laser desorption/ionization time of flight mass spectrometry. J. Dairy Sci. 2019, 102, 2515-2524. [CrossRef] [PubMed]

16. Pichon, B.; Hill, R.; Laurent, F.; Larsen, A.R.; Skov, R.L.; Holmes, M.; Edwards, G.F.; Teale, C.; Kearns, A.M. Development of a real-time quadruplex PCR assay for simultaneous detection of nuc, Panton-Valentine leucocidin (PVL), mecA and homologue mecALGA251. J. Antimicrob. Chemother. 2012, 67, 2338-2341. [CrossRef] 
17. Rola, J.G.; Sosnowski, M.; Ostrowska, M.; Osek, J. Prevalence and antimicrobial resistance of coagulase-positive staphylococci isolated from raw goat milk. Small Rumin. Res. 2015, 123, 124-128. [CrossRef]

18. Eriksson, J.; Espinosa-Gongora, C.; Stamphøj, I.; Larsen, A.R.; Guardabassi, L. Carriage frequency, diversity and methicillin resistance of Staphylococcus aureus in Danish small ruminants. Vet. Microbiol. 2013, 163, 110-115. [CrossRef]

19. Obaidat, M.M.; Salman, A.E.B.; Roess, A.A. High prevalence and antimicrobial resistance of mecA Staphylococcus aureus in dairy cattle, sheep, and goat bulk tank milk in Jordan. Trop. Anim. Health Prod. 2018, 50, 405-412. [CrossRef]

20. Caruso, M.; Latorre, L.; Santagada, G.; Fraccalvieri, R.; Miccolupo, A.; Sottili, R.; Palazzo, L.; Parisi, A. Methicillin-resistant Staphylococcus aureus (MRSA) in sheep and goat bulk tank milk from Southern Italy. Small Rumin. Res. 2016, 135, 26-31. [CrossRef]

21. Cortimiglia, C.; Bianchini, V.; Franco, A.; Caprioli, A.; Battisti, A.; Colombo, L.; Stradiotto, K.; Vezzoli, F.; Luini, M. Short Communication: Prevalence of Staphylococcus aureus and methicillin-resistant S. aureus in bulk tank milk from dairy goat farms in Northern Italy. J. Dairy Sci. 2015, 98, 2307-2311. [CrossRef]

22. Moura, G.S.; Gebreyes, W.A.; Marques, M.F.S.; Stipp, D.T.; Souza, F.N.; Da Costa, L.B.; Oliveira, C.J.B. Short communication: Occurrence of methicillin-resistant Staphylococcus aureus and coagulase-negative staphylococci in dairy goat herds in Ohio, United States. J. Dairy Sci. 2018, 101, 7804-7807. [CrossRef] [PubMed]

23. El-Deeb, W.; Fayez, M.; Elmoslemany, A.; Kandeel, M.; Zidan, K. Methicillin resistant Staphylococcus aureus among goat farms in Eastern province, Saudi Arabia: Prevalence and risk factors. Prev. Vet. Med. 2018, 156, 84-90. [CrossRef] [PubMed]

24. Abreu, R.; Rodríguez-Álvarez, C.; Lecuona, M.; Castro-Hernández, B.; González, J.C.; Aguirre-Jaime, A.; Arias, A. Prevalence and characteristics of methicillin-resistant staphylococci in goats on the Island of Tenerife, Spain. Acta Vet. Hung. 2019, 67, 317-326. [CrossRef]

25. Omoshaba, E.O.; Ojo, O.E.; Oyekunle, M.A.; Sonibare, A.O.; Adebayo, A.O. Methicillin-resistant Staphylococcus aureus (MRSA) isolated from raw milk and nasal swabs of small ruminants in Abeokuta, Nigeria. Trop. Anim. Health Prod. 2020, 52, 2599-2608. [CrossRef] [PubMed]

26. Swedish Veterinary Society. Guidelines for the Use of Antibiotics in Production Animals. Cattle, Pigs, Sheep and Goats. Available online: https:/ / www.svf.se/media/vd5ney4l/svfs-riktlinje-antibiotika-till-produktionsdjur-eng-2017.pdf (accessed on 20 January 2021).

27. Persson, Y.; Järnberg, Å.; Humblot, P.; Nyman, A.K.; Waller, K.P. Associations between Staphylococcus aureus intramammary infections and somatic cell counts in dairy goat herds. Small Rumin. Res. 2015, 133, 62-66. [CrossRef]

28. Goats 2018. Statistics from the Swedish Board of Agriculture. Statistic Report 2019:01. Available online: https:/ /jordbruksverket. se/download/18.29196bdf172db848a9e1384f/1592839852350/201901.pdf (accessed on 20 January 2021). 